\title{
11
}

\section{CONSPIRACY BELIEFS}

\section{Knowledge, ego defense, and social integration in the processing of fake news}

\section{Dolores Albarracín}

Fake news must not be difficult to come across because it took me six minutes to find this quote:

It has been 15 months since a senior CDC scientist, Dr. William Thompson, became a whistleblower when he admitted that a 2004 CDC study was falsified in order to show that there was no link between the MMR vaccine and autism. In August of 2014 Dr. Thompson stated, "I regret that my coauthors and I omitted statistically significant information in our 2004 article published in the Journal of Pediatrics".

Folks, we have a whistleblower at the CDC who has admitted, under oath that the CDC falsified data in order to deny a link between vaccinations and autism. Furthermore, Dr. Thompson has stated that senior CDC researchers tried to destroy all documents related to this cover-up. Dr. Thompson has saved these documents. It is nearly 15 months later and nothing has happened.

(https://healthimpactnews.com/2015/ cdc-cover-up-of-autism-and-vaccine-link-continues/)

Should we really believe that there is evidence that the MMR (Measles, Mumps, and Rubella) vaccine causes autism and also that this evidence has been covered up? Conspiracy beliefs such as those promoted in "fake news" set a double bind in which we are told to both (1) believe the information on the basis of evidence and (2) be satisfied with imperfect verification because the evidence has been covered up. Because of this double bind, conspiracy theories propose a pseudoreality that is plausible or nearly scientific while retaining the appeal of magical thinking and anticipating that the truth may never come to light. The model I present in this chapter describes how such conspiratorial arguments and 

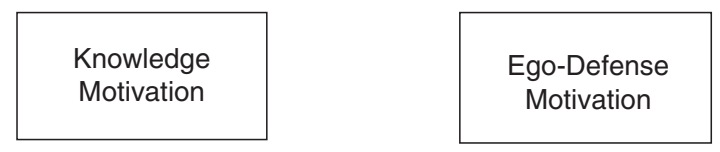

Social Integration Motivation

Verifiable

Unverifiable

FIGURE 11.1 The verifiability continuum and human motivations

related misinformation acquire plausibility and unfalsifiability in relation to the needs for knowledge, ego defense, and social integration. The knowledge motivation is the goal to form accurate and complete representations of the world. The ego defense motivation is the goal to defend the self from unpleasant emotional feelings such as fear. The social integration motivation is the goal to get along with and be valued by other people.

I first classify beliefs in terms of verifiability and place conspiracy beliefs and theories on this verifiability continuum. I then proceed to review how conspiracy theories and other propositions common in fake news connect with (1) the need for knowledge, (2) the need for ego defense, and (3) the need for social integration. If only one of these motivations was implicated, these beliefs would probably not be nearly as seductive. However, conspiracy theories allow news recipients to "have their cake and eat it too" by feeling "informed" while also indulging in convenient lies that appeal to their ego or keep them socially connected at the expense of accuracy. The framework guiding the chapter appears in Figure 11.1.

\section{Belief verifiability}

Beliefs can be (1) verifiable or (2) unverifiable. The verifiable end includes propositions based on direct observation through the senses and the scientific method. Scientific groups, for example, are bound together by a shared, explicit method of verification. Investigative journalism has similar principles in areas of political, educational, or financial concern. Within verifiable beliefs, misconception refers to a belief that is purported to be correct but has no correspondence with reality (Chan, Jones, \& Albarracín, 2017). Many misconceptions are at the center of social groups (e.g., "anti-vaxers") that reinforce the misconceptions. A theory is an organized set of assumptions that guide predictions about reality in a systematic way. Scientific theories use the scientific method of systematic observation, obtaining replications of the observations, comparing conditions, and debating conclusions in the open. 
The unverifiable end includes (1) conspiratorial theories and (2) religious theories that involve nonsystematic and indirect forms of evidence gathering. A conspiracy theory of the type that abounds in fake news is a structure of beliefs stating that powerful hidden forces are responsible for events covered up by these forces (Douglas, Sutton, Jolley, \& Wood, 2015; Enster, 1999; Groh, 1987; Pratt, 2003; van Prooijen \& Krouwel, 2015). Conspiracy theories have devices that inoculate members against potential attacks, namely instilling distrust in information coming from external sources. These belief structures are strong and resistant to verification.

Religious beliefs are supported by a supernatural entity and can have either a weak structure or a strong structure. Weak systems have several interrelated beliefs but are typically simpler and/or less organized, and lack mechanisms to block disconfirming information. For example, universalism describes a number of "new age" beliefs, paganism, and tribal religions in which the universe or the earth are the deity. Universalism also involves systems in which God is perceived to be in all objects, or in all people. Universalist systems are generally loose and do not exist as a written code of behavior, nor do they prescribe all outside beliefs to be wrong.

Strong religious systems, such as sects are offshoots from a larger religious system and emphasize the unique legitimacy of the group's beliefs and practices (Meagher \& O'Brien, 1979). Sects maintain firm boundaries with the rest of society and the larger group from which the sect is separated. The Boko Haram group in Nigeria is an example of a sect because it defined itself as a dissident group, rejected traditional education, and increased secrecy and reliance on privileged knowledge. Second, fundamentalism entails strict and literal adherence to religious texts. For example, Billy Graham's Evangelistic Association supports a literal interpretation of the bible (e.g., the story of creation) through a mass media empire. Islamic extremism is of course common as well. Examples include the Kharijites from the seventh century and the Wahhabi fundamentalism presumably promoted by Saudi Arabia, Pakistan, and Qatar (Braswell, 2000; DelongBas, 2008; Huff, 1995; Nasir, 2009). All of these belief systems are strong in terms of unverifiability because they involve revealed truths but also discourage followers from seeking change.

\section{Verifiability continuum and human motivations}

The verifiability continuum appears in Figure 11.1 and provides an interesting framework to understand how beliefs can serve different types of motivations. On the left end, the most verifiable beliefs serve primarily a knowledge function because they can be aligned with reality. On the right end, the least verifiable beliefs should serve primarily social-integration functions because we need others to tell us stories about secret or spiritual worlds. At the center, both verifiable and unverifiable beliefs serve ego-defense functions, the verifiable because of the action-control functions of the ego (i.e., the need for effective action and 
outcome control) and the unverifiable because of purely defensive functions of the ego. Verifiable beliefs benefit action control when navigating reality, and unverifiable ones sustain us in our convenient illusions.

Given the considerations in Figure 11.1, conspiracy theories may serve any of these functions and are located, as we suggest, at the midpoint between verifiability and unverifiability. They are close enough to verifiability to be plausible, but also unfalsifiable enough to be unverifiable. In an analysis of tweets with vaccination contents, we (Palmer \& Albarracín, 2018) classified the tweets in terms of anti- and pro-vaccination across two domains: MMR and HPV (Human Papilloma Virus) vaccines. As shown, the level of scientific content was quite prevalent and only slightly less so in the anti- than pro-vaccine posts. These data are presented in Table 11.1 and indicate that some conspiracy theories are argued in a way that makes them appear scientifically plausible, and thus closer to the left end of verifiability in Figure 11.1. At the same time, however, the prevalence of contents denouncing a cover-up demonstrate that "anti-vax" contents were also unverifiable because belief of a cover-up removes an audience's ability to judge information. The subterfuge is to place conspiratorial messages in limbo by making them both verifiable and unverifiable at the same time.

We gathered additional data showing that conspiracy theories are different from true conspiracies in both plausibility and unfalsifiability. In a series of studies, we asked participants to rate the theories, some true, some false, by judging their beliefs, as well as the perceived plausibility and unfalsifiability of each theory. The false theories included:

(1) Barak Obama was not born in the US; he faked his birth certificate to become president.

(Politico, 2011)

(2) Illegal immigrants voting illegally prevented Republicans from winning the popular vote in 2016.

(Business Insider, 2018)

(3) The US government created the HIV epidemic by experimentally injecting the virus in people of African descent.

(Heller, 2015)

TABLE 11.1 Features of vaccine-relevant tweets

\begin{tabular}{llclc}
\hline Feature & \multicolumn{2}{l}{ HPV vaccine } \\
& $N=857$ & & $N=737$ & \\
& Anti & Pro & Anti & Pro \\
Scientific content & $16 \%$ & $18 \%$ & $14 \%$ & $16 \%$ \\
Denouncing a cover-up & $18 \%$ & $0 \%$ & $8 \%$ & $0 \%$ \\
\hline
\end{tabular}


(4) The MMR vaccine causes autism but this has been covered up by the US government.

(Eggertson, 2010)

(5) Hillary Clinton ran a pizza-parlor child-sex ring in Washington, D.C.

(Rolling Stone, 2017)

(6) Lizard aliens hybridized with humans who now occupy positions of power.

(goo.gl/T79SzH)

Each of these theories had a true counterpart. For example, the pizza-parlor theory has Clinton using her private server for classified communications as its corresponding true event. Overall, although there was great variability in belief in the presented theories, participants believed in true theories more than false ones. Furthermore, we were able to study the correlations of beliefs with plausibility and unfalsifiability. Plausibility was defined as understanding why the type of situation would happen and remembering other historical examples of the situation. Unfalsifiability was defined as belief that contradictory evidence was the product of a cover-up or was false. Analyses showed overall healthy associations of beliefs with each dimension, although unfalsifiability correlated more positively with beliefs in conspiracies theories than with other beliefs. As predicted from the fact that conspiratorial beliefs are partly verifiable and partly unverifiable, both dimensions were important.

In the upcoming sections, I explain how conspiracy theories are sustained by the knowledge, ego defense, and social integration motives. Consider first the importance of the knowledge motivation. We build theories because they are useful explanations of our observations about reality. The stars in the sky have held a strong grip on lay people, philosophers, and scientists, all of whom have attempted to explain disconcerting observations: astronomical objects disappearing, growing larger, changing the way in which they move, etc. "Retrograde movement", for example, is the observation that planets occasionally appear to move backwards in the firmament. Ptolomeo had to create an elaborate explanation of retrograde movement because his model asserted that planets and stars move forward around the earth. His explanation involved a complicated arrangement of circles, in which a planet would rotate around the earth following a circular orbit. At some point, however, the planet would enter a small loop before resuming its trajectory around the main orbit. In entering this loop, the planet, which was always moving forward, would "appear" to be moving backwards when somebody observed it from earth.

Complicated explanatory models like Ptolomeo's are often abandoned in favor of a more parsimonious explanation. A case in point is Copernicus's explanation of retrograde movement. He revolutionized the scientific and religious understanding of the universe by proposing that the earth orbits around the sun. The velocity of rotation and the orbits themselves, however, differ, creating the 
illusion of retrograde movement as the earth moves at a faster speed than other bodies. In this case, a more straightforward explanation replaced the prior one.

Of course, Ptolomeo's theory was a perfectly useful explanation of the movement of celestial bodies in the sky. Explaining why the theory was replaced even though it was useful and well accepted socially requires a consideration of the concept termed epistemic motivation (Kruglanski, 1989, 1990; Kruglanski, Dechesne, Orehek, \& Pierro, 2009; Kruglanski, Orehek, Dechesne, \& Pierro, 2010), which many others have labeled as accuracy motivation (Hart et al., 2009). According to the concept, humans seek knowledge for the sake of knowledge, even if it has no practical use. The knowledge motivation is at the basis of both accurate beliefs and misconceptions. Knowledge motivation seems more appropriate a term than accuracy motivation because knowledge and information span the spectrum from inaccurate to accurate. The New York Times writer William Davies (2016) titled a description of the 2016 presidential campaign in the United States as "The Age of Post-Truth Politics". In his view, the tendency to represent society in terms of facts began with the introduction of accounting at the end of the medieval age. Before that time, however, facts were not as important because knowledge and truth were revealed in nonliteral fashion, which superseded the more trivial realm of facts.

In addition to knowledge, we are driven by ego-defense motivation, which is the goal to defend the self from unpleasant feelings, such as the disappointment, shame, or sadness that may arise from behaving in incompetent or socially reproachable ways. A vast literature centered on self-enhancement and motivated reasoning suggests that people accommodate their beliefs to their psychological need of self-enhancement (Baumeister, 1997; Eagly \& Chaiken, 1993; Kunda, 1990; Tesser, 2001). For example, they self-defend by rejecting or modifying information that diminishes their perceived self-worth. But the ego is also concerned with action and adaptation to reality. From that point of view, the motivation to act also balances the motivation to know, such as when we are forced to make decisions with necessarily incomplete information.

The knowledge and ego-defense needs trigger goals that set several critical psychological processes in motion, including bringing concepts into focus, employing rudimentary reasoning tools like heuristics and mindsets, and deploying more effortful analysis of information. In turn, progress through these stages depends on the level of confidence people seek, or what Shelly Chaiken (see Chaiken \& Maheswaran, 1994; Chen \& Chaiken, 1999; Chen, Duckworth, \& Chaiken, 1999) termed "confidence thresholds". A relatively low desired level of confidence should lead to concept activation and rudimentary reasoning processes. A higher level of desired confidence will cause people to engage in deeper analytical reasoning until actual confidence reaches the desired confidence threshold.

Confidence thresholds are important for both knowledge and ego-defense motivation. People who seek to gain a thorough understanding of a problem 
will first activate concepts and attempt to apply heuristics. If the heuristics satisfy their desired level of confidence, people are likely to arrive at a judgment based on the heuristic. In contrast, if the desired level of confidence is not met, people are likely to continue with more effortful analysis of information, ending when they reach their desired confidence threshold. Even though these mechanisms follow from both knowledge and ego-defense motivation, additional processing has different effects depending on the motivation type. When knowledge is sought, higher processing produces a more complete, unbiased understanding. However, when ego defense is sought, higher processing simply rationalizes a desired conclusion.

People also strive to be integrated socially, and this need also influences their beliefs. For example, believing that our ancestors protect us from the afterlife may strengthen our ego but also may give us a spiritual form of social integration. Moreover, many conspiracy beliefs, and most scientific beliefs, create automatic social connections with a community of fellow believers.

\section{Conspiracy theories and need for knowledge}

Understanding reality involves constructing knowledge and making judgments that are inherently subjective. Knowledge is what we believe to exist independently of ourselves: we write with the certainty that the keyboard in front of us exists, and we are similarly certain that we need the correct password to gain access to our computer. In addition to this knowledge, we can make judgments with awareness that they are subjective. Beliefs in God or beliefs quitting smoking is healthy are examples. These beliefs position each person in relation to others but do not describe reality or the absolute probability that a statement is true.

Knowledge, beliefs, and attitudes play a number of key roles, including representing reality, understanding objective features of the world, and comparing those features with subjective standards. For example, a carpenter may measure a future table top as having a three-foot diameter. Whether three feet is large or small, however, cannot be ascertained with a tape measure. Rather, it involves an observer equipped with a mental standard making a judgment that is likely to differ from that of others. Naturally, correct representations of reality allow us to navigate the world outside of ourselves. In this context, the convenience of having beliefs is less clear and brings us to an important point: we form beliefs when we need to predict the unknown to realize a goal ("I believe that Mary will attend the conference so I will try to set up a time to talk with her then"). We are looking for an approximation that will allow us to act and pursue goals with the recognition that we lack exact knowledge in a particular case. Attitudes allow us to understand that a house cat is safer than a lion, that certain objects are edible whereas others are not, and that some people will reward us whereas others will punish us.

But do conspiracy theories also facilitate our understanding of the world? Yes, considerable research suggests that this is the case. There are three predictors of 
conspiracy theories that point to that conclusion, including (1) the tendency to perceive patterns, (2) uncertainty, and (3) the need to reduce uncertainty.

\section{Tendency to perceive patterns}

Tying the dots when no clear map exists is an important characteristic of conspiracy theories. Thus, factors such as the tendency to perceive patterns has received the attention of researchers. For example, research by Moulding et al. (2016) included various measures of conspiracy theories as well as the Intolerance for Uncertainty Scale (Buhr \& Dugas, 2002) and the Need for Cognitive Closure (Webster \& Kruglanski, 1994). This study also measured the tendency to perceive a pattern of social relations and just distribution of pain. Specifically, the authors included the World Assumptions Scale (WAS; Janoff-Bulman, 1989), which, among other dimensions, assesses perceptions of randomness ("bad events are distributed to people at random"). The measures of belief in conspiracy theories included the Belief in Conspiracy Theories Inventory (Swami, Chamorro-Premuzic, \& Furnham, 2010). This scale involves 1 (completely false) to 10 (completely true) ratings of such items as "The Apollo moon landings never happened and were staged in a Hollywood film studio". The study also included several other conspiratorial measures, all of which had moderate positive correlations with need for closure and the tendency to perceive patterns. More recent research has reached similar conclusions (Van der Wal, Sutton, Lange, \& Braga, 2018; van Prooijen, Douglas, \& De Inocencio, 2018).

\section{Uncertainty}

Conspiracy theories serve a knowledge function because they allow people to perceive the world as organized and predictable (Bale, 2007; Clarke, 2002; Hofstadter, 1964; Miller, 2002; van Prooijen \& Jostmann, 2013). Although any form of explanation serves the knowledge function, conspiracy theories excel in this function because of their monolithic system structure. This type of structure, which I term "strong system", renders a set of explanations unfalsifiable by casting doubt on any evidence against the theory. For example, the theory that alien lizards occupy powerful positions on earth contains mechanisms of evidence invalidation by which aliens are able to shape shift and cover-up any evidence about their existence. This mechanism introduces suspicion concerning any data offered by potential debunkers of the theory and thus prioritize the validity of the conspiratorial advocacy.

Psychologically, uncertainty is defined as a feeling of doubt, which is generally assumed to be at least mildly unpleasant (Wichman et al., 2010). Uncertainty is produced by a discrepancy between the actual level of understanding of an event or phenomenon and the desired level of understanding (Park, 2010). Work conducted by van Prooijen and Jostmann (2013) revealed how uncertainty propels belief in conspiracy theories without affecting other beliefs. In the 
first experiment reported in this paper, participants were induced to experience uncertainty by having them write about either an experience of uncertainty or the experience of watching television. They then read one or two excerpts, one about the personnel policies of oil companies being unethical (labeled "immoral" in the article) and the other about the policies being ethical (labeled "moral" in the article). Even though the excerpts did not specifically discuss a conspiracy, one can expect that an actor described as immoral provides the ideal terrain for a conspiracy theory to fill in the blanks. Thus, after reading the information about oil companies, participants were asked to answer three questions: "Do you believe that oil companies had a vested interest in the war in Iraq?", "Do you believe that oil companies helped to cause the war in Iraq?", and "To what extent do you believe that people who are associated with oil companies gave the order to start the war in Iraq?" Responses to these items had high internal consistency and were averaged as a measure of belief in conspiracy theories.

The hypothesis that guided van Prooijen and Jostmann's (2013) first experiment was that states of uncertainty will lead to spontaneously believing in conspiracies for unethical (vs. ethical) actors even though no conspiratorial information was presented. However, in the absence of uncertainty, the researchers expected no difference between the unethical and ethical conditions. In this experiment, participants were more likely to deduce a conspiracy when an actor was perceived as generally unethical (vs. ethical), but this effect was only present when uncertainty was made accessible.

The results of Experiment 1 were reproduced in a second experiment with the same uncertainty manipulation but describing the government of an African city to be corrupt or law-abiding. After this description, participants learned that a candidate for presidential elections opposed the government and had died in a car accident. Again, if people who feel uncertain construct a conspiracy theory as a way of reducing uncertainty, unethical actors should lead to greater endorsement of conspiratorial interpretations than ethical ones. As shown by the findings, this was in fact the case.

More indirect evidence of the effect of uncertainty comes from research on the effects of ambivalence on endorsement of conspiracy beliefs. Van Harreveld, Rutjens, Schneider, Nohlen, and Keskinis (2014) manipulated ambivalence by asking research participants to describe an issue or opinion that personally elicited ambivalence or unequivocal points of view. Participants then rated the degree to which work or financial outcomes described in a vignette were related to the actions of others. Findings indicated that the ambivalence manipulation indeed produced ambivalence as well as negative affect in relation to the ambivalence. Moreover, the unpleasant feelings associated with doubt in turn increased conspiracy beliefs.

\section{Need to reduce uncertainty}

Uncertainty alone would have little effect if humans could be content without certainty, and individuals certainly vary in their need to reduce uncertainty. 
Thus, not surprisingly, a number of studies has examined the relation between this individual difference and misconceptions. The need to reduce uncertainty is often measured with the Intolerance of Uncertainty Scale (Carleton, Norton, \& Asmundson, 2007; Freeston, Rhéaume, Letarte, Dugas, \& Ladouceur, 1994) with statements like "I can't stand being taken by surprise" on a 5-point Likert scale $(1=$ not at all characteristic of me to $5=$ entirely characteristic of $m e)$. Another popular measure is the Need for Cognitive Closure Scale (Roets \& Van Hiel, 2011; Webster \& Kruglanski, 1994), with statements such as "I dislike unpredictable situations" measured on a 6-point Likert-type scale $(1=$ Strongly Disagree to $6=$ Strongly Agree). The latter scale has a close relative, the Uncertainty Orientation Scale (Sorrentino \& Short, 1986), which was apparently the result of a close collaboration by teams that eventually parted ways. Any of these measures could be predicted to show a positive association with conspiracy theories.

Contrary to expectations though, the scientific data have shown only tenuous support for a direct association between conspiracy theories and the need to reduce uncertainty. Recall that van Prooijen and Jostmann's (2013) study included five measures of conspiracy theory endorsement. With this level of thoroughness, the study provides excellent data to determine the degree to which belief in conspiracy theories correlate with need for closure and intolerance of uncertainty. However, the data were disappointing as only the association between the Conspiracy Mentality Questionnaire and the Intolerance for Uncertainty Scale was significant.

Weak associations between need for cognitive closure and conspiracy theory endorsement could be attributed to either a lack of true link between the two or to nonlinear associations. A likely candidate for such a nonlinear association is an interaction between need for cognitive closure, a chronic predisposition to make conspiratorial attributions, and available evidence at the time of making a judgment. Leman and Cinnirella (2013) investigated exactly this question by administering Swami et al.'s (2010) Belief in Conspiracy Theories Inventory as a measure of chronic conspiracy disposition and the Need for Closure Scale to college students in the United Kingdom. In addition, the authors presented ostensible evidence about a plane crash leading to five fatalities, one of whom was a political figure the opposition wanted to block. The evidence either did or did not imply a conspiracy.

If need for cognitive closure is high, one would expect the audience to want to reach a definitive conclusion by using the available evidence. Thus, chronically high conspiracy endorsers who are also high in need for closure should be more likely to attribute the accident to the conspiracy than low endorsers. Furthermore, high-need for cognitive closure participants who received no evidence of cause for the crash and of suspicious travel-plan changes should assume that a conspiracy took place, whereas high-need for cognitive closure recipients of information that all parties had been satisfied that the crash was an accident should assume that an accident took place. However, people whose need for closure is low may be less quick to reach conclusions and may thus be unaffected by either the information that was supplied to them or their chronic conspiratorial thoughts. 
The results from Leman and Cinnirella's (2013) experiment conformed to expectations about chronic conspiracy endorsement. Overall, both habitually suspecting conspiracies and receiving information favoring a conspiracy increased the probability of participants suspecting foul play. However, need for cognitive closure moderated the influence of the chronic endorsement of conspiracy theories. People high in need for cognitive closure were more likely to make conspiracy attributions when they scored high (vs. low) on Belief in Conspiracy Theories Inventory (approximately $M \mathrm{~s}=34$ vs. 30 on a scale of $0-50$ ). In contrast, people with low need for cognitive closure were insensitive to the information presented to them (approximately $M=28$ in both cases). This study may thus suggest that need for closure makes people follow their habitual hunches to explain ambiguous information but has little effect when the information is compelling.

In research conducted by Marchlewska, Cichocka, and Kossowska (2017), Polish participants underwent procedures similar to those used by Leman and Cinnirella's (2013). In Experiment 1, participants read information about the arrival of refugees into Poland. Generally, need for closure correlated with the belief that the arrival of refugees was part of a conspiracy against Poland $(r=.22)$. Furthermore, the effect of need for closure was stronger when participants were presented with an ostensible internet conversation suggesting that the refugee arrival was part of a conspiracy by the European Union to harm Poland. Importantly, these effects were replicated in a second experiment in which, similar to Leman and Cinnirella's (2013) work, participants were exposed to information about a plane accident.

\section{Conspiracy theories as a form of support for the ego}

A central motivation for believing in conspiracy theories within our conceptualization is the need to bolster the ego. This motivation entails defending the ego from unpleasant thoughts about the self, such as avoiding perceptions that one is malevolent, deceptive, or incompetent. But strengthening the ego also involves ensuring the executive capacities that are necessary for successful action and management of the challenges of life.

\section{Ego defense}

Personality traits associated with schizotypal personality and paranoia dominated the literature on conspiracy theories for decades. From the point of view of psychodynamic theory, schizotypal personality is characterized by omnipotence, idealization, devaluation, denial, primitive projection or projective identification, and splitting. Schizotypal personality also involves autistic fantasy and an absence of repression (Perry, Presniak, \& Olson, 2013). These mechanisms allow individuals to believe that the self is all-powerful and to protect themselves from shame or fear by imagining that others have these thoughts and emotions. Through autistic fantasy, the self can be protected by imagining the world just as 
they would like it to be. When people with schizotypal personality lose contact with reality, delusions of persecution, unwarranted jealousy, or exaggerated selfimportance are common. One can thus speculate that schizotypy and paranoia are the result of the same type of defense mechanisms.

If paranoia is to be the cause of conspiracy theorizing, it is first necessary to demonstrate that the two factors are separate. In an excellent article of this question, Imhoff and Lamberty (2018) synthesized correlations between conspiracy theories and paranoia stemming from 11 studies. These correlations appear in Table 11.2 and are suggestive of separate constructs, which Imhoff and Lamberty confirmed via factor analyses in two additional primary studies.

In one of the studies included in Imhoff and Lamberty's meta-analysis, Darwin et al. (2011) measured adherence to conspiracy theories with an ad-hoc questionnaire containing items like "There are specialized government services who attempt to harass UFO witnesses into silence". They used the Paranormal Belief Scale (PBS; Tobacyk \& Milford, 1983) to measure traditional religious belief, psi beliefs, witchcraft, superstition, spiritualism, extraordinary life forms, and precognition. They also measured paranoid tendencies with the Paranoid Ideation Scale (Fenigstein \& Vanable, 1992), which consists of 20 statements rated from 1 (not at all applicable to me) to 5 (extremely applicable to $m e$ ) measuring thoughts that others want to harm the respondent. They also administered the Schizotypal Personality Questionnaire (SPQ), which includes 22 items and subscales for cognitive-perceptual deficits, interpersonal deficit, and disorganization. An inspection of these data in Table 11.3 suggests considerable shared variance between conspiracy theorizing and each of these scales, particularly parapsychology and paranoid ideation. Causal modeling analyses revealed that the best fitting model was one in which the overall schizotypy score influenced conspiracy theorizing, both directly and via

TABLE 11.2 Correlations between conspiracy theories and paranoia

\begin{tabular}{ll}
\hline Study & $r$ \\
\hline Barron, Morgan, Towell, Altemeyer, and Swami (2014) & 0.24 \\
Brotherton and Eser (2015) & 0.52 \\
Bruder, Haffke, Neave, Nouripanah, and Imhoff (2013), Study 2 & 0.45 \\
Bruder et al. (2013), Study 3 & 0.5 \\
Cichocka, Marchlewska, and Golec de Zavala (2016) & 0.37 \\
Darwin, Neave, and Holmes (2011) & 0.47 \\
Grzesiak-Feldman and Ejsmont (2008) & 0.62 \\
Grzesiak-Feldman (2015) & 0.3 \\
Wilson and Rose (2014), Study 1 & 0.27 \\
Wilson and Rose (2014), Study 2 & 0.27 \\
Wilson and Rose (2014), Study 3 & 0.29 \\
Wilson and Rose (2014), Study 4 & 0.3 \\
\hline
\end{tabular}


TABLE 11.3 Correlations between conspiracy beliefs, religious beliefs, various paranormal beliefs and abnormal perceptions

\begin{tabular}{ll}
\hline & $\begin{array}{l}\text { Conspiracy score } \\
(\mathrm{N}=120)\end{array}$ \\
\hline Religious belief & $.26^{*}$ \\
PSI (Parapsychology) & $.53^{* *}$ \\
Witchcraft & $.40^{* *}$ \\
Spiritualism & $.43^{* *}$ \\
Superstition & $.22^{*}$ \\
Extraordinary life forms & $.30^{*}$ \\
Precognition & $.22^{* *}$ \\
Total paranormal belief score & $.47^{* *}$ \\
Paranoid ideation & $.47^{* *}$ \\
Cognitive-perceptual deficits & $.31^{* *}$ \\
Interpersonal deficit & $.19^{*}$ \\
Disorganization & $.27^{*}$ \\
Total schizotypy score & $.34^{* *}$ \\
\hline
\end{tabular}

$*: p<.05, * *: p<.01$

Source: Adapted from Darwin et al., 2011

mediating influences on paranoid ideation. This model, however, did not include the Paranormal Belief Scale.

\section{Anxiety and support for action}

The need to exercise control over one's environment has been outlined as a key factor in conspiracy theory endorsement. The hypothesis of control states that people's tendency to introduce purpose and order into their worlds stems from the need to exercise control and facilitates beliefs in conspiracy theories. Hofstadter (1964) pointed out that conspiracy beliefs help powerless or voiceless individuals to understand their disadvantaged social reality (see also Bale, 2007). Consistently, past findings indicate that the motivation to make sense of threatening events within a community increases belief in conspiracy theories (van Prooijen \& van Dijk, 2014; see also van Prooijen \& van Lange, 2014). Control applies to social threats but also to a general desire to retain control over any aspects of the world and has led to research on meaning-making (Heine, Proulx, \& Vohs, 2006; Park, 2010; van den Bos, 2009) and compensatory control (Kay, Whitson, Gaucher, \& Galinsky, 2009; Rutjens, van Harreveld, \& van der Pligt, 2013). The more disturbing an event is, or the greater the loss of control, the more likely that people will endorse conspiratorial interpretations of the event (Mccauley \& Jacques, 1979; Pipes, 1997; Robins \& Post, 1997; Shermer, 2011; J. van Prooijen \& van Dijk, 2014). 
Perceptions of personal control protect us from the disorienting randomness of our lives (Lerner, 1980). According to Kay et al. (2009), humans have an arsenal of compensatory psychological mechanisms to preserve a sense of order even when actual control is not possible (see also Axt, Landau, \& Kay, this volume). A compensatory perceptual reorganization of the world as orderly seems a consequence of the experience of anxiety associated with decreases in control. To test this possibility, Whitson and Galinsky (2008) had research participants recall experiences of feeling out of control and crossed this manipulation with selfaffirmation. Self-affirmation (Steele, 1988) is often achieved by recalling one's important values and is expected to reduce anxiety and cognitive dissonance. Thus, in the case of activating the feelings associated with control challenges, self-affirmation should restore a sense of control. In this study, participants who were not self-affirmed had stronger beliefs in conspiratorial explanations than did those that recalled non-self-affirming material or nothing at all. In other words, reestablishing one's self-confidence reduced anxiety and eliminated the need to see order in ambiguous events.

One limitation with Whitson and Galinsky's data is the lack of a baseline for the control manipulation. Fortunately, however, van Prooijen and Acker (2015) conducted a similar experiment in which participants wrote about a time when they had felt out of control, in control, or neither. Participants then read some information about the construction of a subway line in Amsterdam and were asked questions about corruption in the construction contract. As in Whitson and Galinsky, participants with low control had stronger conspiracy beliefs than participants with high control. Extending prior findings, baseline participants did not differ significantly from participants with low control but did differ from participants with high control. All in all, threats to control increase the tendency to introduce purpose, meaning, and order into the world at the expense of believing in conspiracies.

Interestingly, van Prooijen and Acker (2015) also reanalyzed prior survey data about suspected Y2K conspiracies. The survey contained measures about the threat of the $\mathrm{Y} 2 \mathrm{~K}$ bug for the smooth functioning of computer systems around the world as well as a range of conspiracy beliefs about the Kennedy assassination and the cover-up of evidence for the existence of extraterrestrial life, among other conspiracies. The degree to which respondents felt threatened by $\mathrm{Y} 2 \mathrm{~K}$ correlated with their beliefs in various conspiracy theories that were completely unrelated to $\mathrm{Y} 2 \mathrm{~K}$, suggesting that any perceived threat is likely to ignite conspiratorial explanations of events. Interestingly, a perceived Y2K threat was negatively correlated with the belief that a conspiracy surrounded the Y2K bug. This negative association may suggest that people who felt a greater threat were also better informed about the causes of Y2K. Alternatively, the obvious connection between the two measured could have led participants to alter their judgment about the conspiracy in an effort to correct for the influence of their emotions. 
A more general demonstration of associations between conspiracy theory endorsement and stress was provided in a correlational study by Swami and colleagues (2016). The researchers collected data from US adults who participated in Amazon Mechanical Turk. Participants filled out the Belief in Conspiracy Theories Inventory, as well as the Perceived Stress Scale (Cohen, Kamarck, \& Mermelstein, 1983), the List of Threatening Experiences Questionnaire (Brugha, Bebbington, Tennant, \& Hurry, 1985), Form Y-1 of the State-Trait Anxiety Inventory (Spielberger, Gorsuch, Lushene, Vagg, \& Jacobs, 1983) as a measure of state anxiety, Y-2 of the State-Trait Anxiety Inventory (Spielberger et al., 1983) as a measure of trait anxiety, and the Profile of Mood States (Shacham, 1983). Perceived stress, stressful life events, and trait anxiety correlated positively with conspiracy theory endorsement ( $r$ s $=.10$ to .29).

One form of anxiety that has received attention in the literature has been insecure attachment. People with secure (vs. insecure) attachment seek instrumental and emotional support from others (Florian, Mikulincer, \& Taubman, 1995; Larose, Bernier, Soucy, \& Duchesne, 1999). People with insecure attachment may avoid (avoidant attachment) or intensely seek proximity with others. Anxious individuals tend to exaggerate the threats they encounter as a form of gaining support from others and are hypervigilant in interpersonal domains (Cassidy \& Berlin, 1994; Cassidy \& Kobak, 1988; Mikulincer, Shaver, \& Pereg, 2003). Green and Douglas (2018) investigated the possibility that the hypervigilance associated with anxious attachment may be associated with conspiracy theories as an attempt to reduce anxiety (Douglas, Sutton, \& Cichocka, 2017). To test this hypothesis, Green and Douglas administered questionnaires measuring beliefs in conspiracy theories and in the general tendency for powerful groups to conspire, as well as attachment. As predicted, anxious attachment predicted conspiratorial thinking even after controlling other interpersonal and political variables.

The effects of reduced control, anxiety, stress, and attachment style on conspiracy theories are likely to not only be unpleasant but also problematic for the enactment of action. In fact, cognitive dissonance has been proposed to exert effects not because of the experience of anxiety but because of the action disruption produced by those feelings (Harmon-Jones, Harmon-Jones, \& Levy, 2015). As beliefs and attitudes automatically promote actions, conflict arises if those beliefs and attitudes have opposing implications. Thus, sustaining actions in a relatively orderly way is likely to be the factor that underlies many of the findings associated with reductions in perceived control.

\section{Self-esteem and narcissism}

Self-esteem maintenance has been argued to be at the basis of conspiracy theories, assuming that explanations and seeing the negatives outside of the self is comforting (Robins \& Post, 1997). A number of studies have measured self-esteem and correlated it with measures of conspiracy theories. In a study conducted in the 
UK and Austria (Swami et al., 2011), for example, participants completed measures of conspiracy theory and self-esteem. Belief in a 7/7 conspiracy and a general conspiracy theory inventory correlated with self-esteem $r=-.16$ and -.20 , supporting the hypothesis that people with low self-esteem endorse conspiratorial ideas more than people with high self-esteem, which replicated in a second study with a fictitious conspiracy theory as well as in other research (Galliford \& Furnham, 2017). This seemingly robust finding, however, has two possible explanations. On the one hand, low self-esteem may increase these beliefs as an attempt to improve positive feelings about the self. On the other, low self-esteem may simply color people's views of the world in a negative way.

Research conducted by Cichocka, Marchlewska, De, and Olechowski (2016) illuminated the processes by which self-esteem influences conspiratorial ideas. Even though the zero-order correlations between self-esteem and conspiracy theories were not statistically significant, self-esteem predicted belief in them when controlling for narcissism. Interestingly, however, narcissism had a consistent positive association with conspiracy theories. Specifically, narcissists are more likely than non-narcissists to see themselves as envied and conspired against by others, a paranoia that in turn predicts beliefs in conspiracy theories.

The three studies reported by Cichocka et al. (2016) supported the idea that narcissism correlated positively with conspiracy theories (e.g., $r=.25$ in Study 2) and paranoia (e.g., $r=.18$ in Study 2 ), and that some of the influence of narcissism on conspiracy theories is mediated by paranoia. In contrast, low self-esteem is associated with lower paranoia, possibly because seeing oneself as the center of a conspiracy requires perceiving that one is valuable. Moreover, self-esteem correlated with esteem for humanity, implying that a person's self-value predicts general positivity toward others.

All of the research on self-esteem and narcissism is naturally correlational but the related variable of need for uniqueness has been varied using experimental procedures. Need for uniqueness is the desire to be different from others and stand out for unique characteristics and ideas (Lynn \& Snyder, 2002). Conspiracy theories are ideal markers of uniqueness because they are relatively unconventional and suggest access to privileged knowledge (Lantian, Muller, Nurra, \& Douglas, 2017). Participants who wrote about a past instance of individuality, as opposed to conformity, reported stronger conspiratorial interpretations of an accident (Lantian et al., 2017). In this light, it seems possible that the positive association between narcissism and conspiracy theories is also due to many narcissists' tendency to see themselves as intellectually superior and thus better able to perceive difficult-to-detect plots (for research in the area of collective narcissism, see Golec de Zavala \& Federico, 2018).

\section{Conspiracy theories as a form of social integration}

Conspiracy theories are a social phenomenon, whereas paranoia comprises individual ideas. As other social phenomena then, we should consider the social 
motives that strengthen conspiratorial thought, many of which have been investigated in the literature. Of course, many of the social factors implicated in conspiracy theories are political, but the effects of isolation and exclusion are generally related to the need to be integrated socially in informal networks.

Isolation and social exclusion have been prime explanatory variables in the study of conspiracy theories but the evidence is not without ambiguities. On the one hand, isolation and social exclusion appears to strengthen beliefs in conspiracy theories by increasing anxiety and need to simplify the world. Graeupner and Coman (2017) investigated this possibility in two studies, one correlational and the other experimental. The correlation between feelings of exclusion and endorsement of conspiracy theories was $r=.19$. On the other hand, connections and concern with groups can increase consideration of such social threats as those depicted in conspiracy theories. In fact, Graeupner and Coman's second study showed that being ostensibly selected as a partner for an experimental task (the manipulation of exclusion) led to higher conspiratorial attributions than not being selected, an effect equal to $r=.25$.

\section{Summary}

The review presented in this chapter suggests that the scholarship on how arguments acquire plausibility and unfalsifiability is nascent and that research attention is warranted. In particular, the literature is populated with studies based on college students and nonrepresentative samples. Moreover, research has not paid sufficient attention to the degree to which social media and other digital technologies contribute to the dissemination of conspiracy theories and other pernicious forms of fake news. In the future, more diverse national samples and research different technologies should shed further light on the post-truth era in which we live.

In this chapter, I proposed that conspiracy theories are a fascinating case of an argument that is predicated on the basis of both verifiability and unverifiability. These two poles connect conspiracy theories with all fundamental human needs: the need for knowledge, the need for ego defense, and the need for social integration. In so doing, conspiracy theories provide a pseudo-reality that is plausible or nearly scientific but retains the mystery of cover-ups. This marriage makes these beliefs quite enduring and challenging to correct.

\section{References}

Bale, J. M. (2007). Political paranoia v. political realism: On distinguishing between bogus conspiracy theories and genuine conspiratorial politics: Patterns of prejudice (Vol. 41). Graduate School of International Policy Studies, Monterey Institute of International Studies. Monterey, CA, US: Taylor \& Francis. http://dx.doi.org/10.1080/00313220601118751

Barron, D., Morgan, K., Towell, T., Altemeyer, B., \& Swami, V. (2014). Associations between schizotypy and belief in conspiracist ideation: Personality and individual differences (Vol. 70). Department of Psychology, University of Westminster. London, United 
Kingdom david.barron@my.westminster.ac.uk; Barron, David, 309 Regent Street, London, United Kingdom, W1B 2UW: Department of Psychology, University of Westminster, david.barron@my.westminster.ac: Elsevier Science. http://dx.doi. org/10.1016/j.paid.2014.06.040

Baumeister, R. F. (1997). Identity, self-concept, and self-esteem: The self lost and found. In Handbook of personality psychology (pp. 681-710). San Diego, CA, US: Academic Press.

Braswell, G. W. (2000). What you need to know about Islam \& Muslims. Nashville, TN: B\&H Publishing Group.

Brotherton, R., \& Eser, S. (2015). Bored to fears: Boredom proneness, paranoia, and conspiracy theories. Personality and Individual Differences, 80, 1-5. https://doi.org/10.1016/j. paid.2015.02.011

Bruder, M., Haffke, P., Neave, N., Nouripanah, N., \& Imhoff, R. (2013, April). Measuring individual differences in generic beliefs in conspiracy theories across cultures: Conspiracy mentality questionnaire. Frontiers in Psychology, 4, 225. https://doi. org/10.3389/fpsyg.2013.00225

Brugha, T., Bebbington, P., Tennant, C., \& Hurry, J. (1985). The list of threatening experiences: A subset of 12 life event categories with considerable long-term contextual threat. Psychological Medicine. https://doi.org/10.1017/S003329170002105X

Buhr, K., \& Dugas, M. J. (2002). The intolerance of uncertainty scale: Psychometric properties of the English version. Behaviour Research and Therapy, 40(8), 931-945. https://doi.org/10.1016/S0005-7967(01)00092-4

Business Insider. (2018). 19 outlandish conspiracy theories Donald Trump has floated on the campaign trail and in the White House. Retrieved from www.businessinsider. com/donald-trump-conspiracy-theories-2016-5\#claims-3000-people-didnt-die-inpuerto-rico-after-hurricane-maria-and-that-democrats-inflated-the-death-toll-19

Carleton, R. N., Norton, M. A. P. J., \& Asmundson, G. J. G. (2007). Fearing the unknown: A short version of the Intolerance of Uncertainty Scale. Journal of Anxiety Disorders. https://doi.org/10.1016/j.janxdis.2006.03.014

Cassidy, J., \& Berlin, L. J. (1994). The insecure/ambivalent pattern of attachment: Theory and research. Child Development. https://doi.org/10.1111/j.1467-8624.1994.tb00796.x

Cassidy, J., \& Kobak, R. R. (1988). Avoidance and its relation to other defensive process. In J. Belsky \& T. Nezworski (Eds.), Child psychology. Clinical implications of attachment (pp. 300-323). Mahwah, NJ: Lawrence Erlbaum Associates.

Chaiken, S., \& Maheswaran, D. (1994). Heuristic processing can bias systematic processing: Effects of source credibility, argument ambiguity, and task importance on attitude judgment. Journal of Personality and Social Psychology. https://doi.org/10.1037/0022-3514.66.3.460

Chan, M. S., Jones, C. R., \& Albarracín, D. (2017). Countering false beliefs: An analysis of the evidence and recommendations of best practices for the retraction and correction of scientific misinformation. In Handbook of the science of science communication. https://doi.org/10.1093/oxfordhb/9780190497620.013.37

Chen, S., \& Chaiken, S. (1999). The heuristic-systematic model in its broader context. In Dualprocess theories in social psychology. https://doi.org/10.4319/lo.2013.58.2.0489

Chen, S., Duckworth, K., \& Chaiken, S. R. (1999). Motivated heuristic and systematic processing. Psychological Inquiry. https://doi.org/10.1207/s15327965pli1001_6

Cichocka, A., Marchlewska, M., De, A. G., \& Olechowski, M. (2016). "They will not control us": Ingroup positivity and belief in intergroup conspiracies, 556-576. https:// doi.org/10.1111/bjop.12158

Cichocka, A., Marchlewska, M., \& Golec de Zavala, A. (2016). Does self-love or self-hate predict conspiracy beliefs? Narcissism, self-esteem, and the endorsement of conspiracy theories: 
Social psychological and personality science (Vol. 7). Canterbury, UK: School of Psychology, University of Kent a.k.cichocka@kent.ac.uk; Institute for Social Studies, University of Warsaw, Warsaw, Poland ; Department of Psychology, Goldsmiths, University of London, London, United Kingdom; Cichock: Sage Publications. http:// dx.doi.org/10.1177/1948550615616170

Clarke, S. (2002). Conspiracy theories and conspiracy theorizing. Philosophy of the Social Sciences. https://doi.org/10.1177/004931032002001

Cohen, S., Kamarck, T., \& Mermelstein, R. (1983). A global measure of perceived stress. Journal of Health and Social Behavior, 24(4), 385-396.

Darwin, H., Neave, N., \& Holmes, J. (2011). Belief in conspiracy theories. The role of paranormal belief, paranoid ideation and schizotypy. Personality and Individual Differences, 50(8), 1289-1293. https://doi.org/10.1016/j.paid.2011.02.027

Davies, W. (2016, August 24). The age of post-truth politics. The New York Times. Retrieved from www.nytimes.com/

Delong-Bas, N. J. (2008). Wahhabi Islam: From revival and reform to global jihad. Oxford: Oxford University Press.

Douglas, K. M., Sutton, R. M., \& Cichocka, A. (2017). The psychology of conspiracy theories. Current Directions in Psychological Science, 26(6), 538-542. https://doi. org $/ 10.1177 / 0963721417718261$

Douglas, K. M., Sutton, R. M., Jolley, D., \& Wood, M. J. (2015). The social, political, environmental, and health-related consequences of conspiracy theories. In M. Bilewicz, A. Cichocka, \& W. Soral (Eds.), The psychology of conspiracy (pp. 183-200). New York and London: Routledge/Taylor \& Francis Group.

Eagly, A. H., \& Chaiken, S. (1993). The psychology of attitudes. Fort Worth, TX: Harcourt Brace Jovanovich College Publishers.

Eggertson, L. (2010). Lancet retracts 12-year-old article linking autism to MMR vaccines. CMAJ : Canadian Medical Association Journal = Journal de l'Association Medicale Canadienne, 182(4). https://doi.org/10.1503/cmaj.109-3179

Enster, M. (1999). Conspiracy theories: Secrecy and power in American culture. St. Paul, MN: University of Minnesota Press.

Fenigstein, A., \& Vanable, P. A. (1992). Paranoia and self-consciousness. Journal of Personality and Social Psychology. https://doi.org/10.1037/0022-3514.62.1.129

Florian, V., Mikulincer, M., \& Taubman, O. (1995). Does hardiness contribute to mental health during a stressful real-life situation? The roles of appraisal and coping. Journal of Personality and Social Psychology. https://doi.org/10.1037/0022-3514.68.4.687

Freeston, M. H., Rhéaume, J., Letarte, H., Dugas, M. J., \& Ladouceur, R. (1994). Why do people worry? Personality and Individual Differences. https://doi.org/10.1016/01918869(94)90048-5

Galliford, N., \& Furnham, A. (2017). Individual difference factors and beliefs in medical and political conspiracy theories: Scandinavian journal of psychology (Vol. 58). Research Department of Clinical, Educational and Health Psychology, University College London. London, UK: Wiley-Blackwell Publishing Ltd. http://dx.doi.org/10.1111/sjop.12382

Golec de Zavala, A., \& Federico, C. M. (2018). Collective narcissism and the growth of conspiracy thinking over the course of the 2016 United States presidential election: A longitudinal analysis. European Journal of Social Psychology. https://doi.org/10.1002/ ejsp.2496

Graeupner, D., \& Coman, A. (2017). The dark side of meaning-making: How social exclusion leads to superstitious thinking: Journal of experimental social psychology (Vol. 69). Princeton, NJ, US: Department of Psychology, Princeton University acoman@princeton.edu; Coman, Alin, Peretsman-Scully Hall, \#529, Princeton, US, 08540, Department of 
Psychology, Princeton University, acoman@princeton.edu: Elsevier Science. http:// dx.doi.org/10.1016/j.jesp.2016.10.003

Green, R., \& Douglas, K. M. (2018). Anxious attachment and belief in conspiracy theories. Personality and Individual Differences, 125, 30-37. https://doi.org/10.1016/j. paid.2017.12.023

Groh, D. (1987). Draft of a theory of conspiracy theories. In Changing conceptions of conspiracy. https://doi.org/10.1007/978-1-4612-4618-3

Grzesiak-Feldman, M. (2015). Are the high authoritarians more prone to adopt conspiracy theories? The role of right-wing authoritarianism in conspiratorial thinking. (M. Bilewicz, A. Cichocka, \& W. Soral, Eds.), The psychology of conspiracy BT: The psychology of conspiracy. New York, NY: Routledge and Taylor \& Francis Group. Retrieved from https:// search.proquest.com/docview/1717508783?accountid=14553

Grzesiak-Feldman, M., \& Ejsmont, A. (2008). Paranoia and conspiracy thinking of Jews, Arabs, Germans, and Russians in a Polish sample: Psychological reports (Vol. 102). Warsaw, Poland: University of Warsaw ika@psych.uw.edu.pl; Grzesiak-Feldman, Monika, Stawki 5/7, Warsaw, Poland, 00-183, Faculty of Psychology, University of Warsaw, ika@psych.uw.edu.pl: Psychological Reports Sage Publications. http://dx.doi. org/10.2466/PR0.102.3.884-886

Harmon-Jones, E., Harmon-Jones, C., \& Levy, N. (2015). An action-based model of cognitive-dissonance processes. Current Directions in Psychological Science. https://doi. org $/ 10.1177 / 0963721414566449$

Hart, W., Albarracín, D., Eagly, A.H., Lindberg, M., Lee, K.H., \& Brechan, I. (2009). Feeling validated vs. being correct: A meta-analysis of exposure to information. Psychological Bulletin, 135, 555-588. doi: 10.1037/a0015701. PMID: 19586162

Heine, S. J., Proulx, T., \& Vohs, K. D. (2006). The meaning maintenance model: On the coherence of social motivations. Personality and Social Psychology Review, 10(2), 88-110. https://doi.org/10.1207/s15327957pspr1002_1

Heller, J. (2015). Rumors and realities: Making sense of HIV/AIDS conspiracy narratives and contemporary legends. American Journal of Public Health, 105(1), e43-e50. https:// doi.org/10.2105/AJPH.2014.302284

Hofstadter, R. (1964, November). The paranoid style in American politics. Harpers Magazine.

Huff, T. E. (1995). Rethinking islam and fundamentalism. Sociological Forum. https://doi. org/10.1007/BF02095834

Imhoff, R., \& Lamberty, P. (2018). How paranoid are conspiracy believers? Toward a more fine-grained understanding of the connect and disconnect between paranoia and belief in conspiracy theories. European Journal of Social Psychology. Mainz, Germany: Johannes Gutenberg University of Mainz roland.imhoff@uni-mainz.de: John Wiley \& Sons. http:// dx.doi.org/10.1002/ejsp.2494

Janoff-Bulman, R. (1989). Assumptive worlds and the stress of traumatic events: Applications of the schema construct. Social Cognition. https://doi.org/10.1521/soco.1989.7.2.113

Kay, A. C., Whitson, J. A., Gaucher, D., \& Galinsky, A. D. (2009). Compensatory control: Achieving order through the mind, our institutions, and the heavens: Current directions in psychological science (Vol. 18). Waterloo, ON, Canada: University of Waterloo ackay@ uwaterloo.ca; University of Texas at Austin, Austin, TX, US; Northwestern University, Evanston, IL, US; Kay, Aaron C., 200 University AveWest, Waterloo, Canada, Department of Psychology, University of Water: Wiley-Blackwell Publishing Ltd. Blackwell Publishing Sage Publications. http://dx.doi.org/10.1111/j.1467-8721.2009.01649.x

Kruglanski, A. W. (1989). Lay epistemics and human knowledge: Cognitive and motivational bases: Perspectives in social psychology. https://doi.org/10.1007/978-1-4899-0924-4 
Kruglanski, A. W. (1990). Lay epistemic theory in social-cognitive psychology. Psychological Inquiry. https://doi.org/10.1207/s15327965pli0103_1

Kruglanski, A. W., Dechesne, M., Orehek, E., \& Pierro, A. (2009). Three decades of lay epistemics: The why, how, and who of knowledge formation. European Review of Social Psychology. https://doi.org/10.1080/10463280902860037

Kruglanski, A. W., Orehek, E., Dechesne, M., \& Pierro, A. (2010). Lay epistemic theory: The motivational, cognitive, and social aspects of knowledge formation. Social and Personality Psychology Compass. https://doi.org/10.1111/j.1751-9004.2010.00308.x

Kunda, Z. (1990). The case for motivated reasoning. Psychological Bulletin. https://doi. org $/ 10.1037 / 0033-2909.108 .3 .480$

Lantian, A., Muller, D., Nurra, C., \& Douglas, K. M. (2017). "I know things they don't know!": The role of need for uniqueness in belief in conspiracy theories: Social psychology (Vol. 48). Grenoble, France: University Grenoble Alpes dominique.muller@univgrenoble-alpes.fr; School of Psychology, University of Kent, United Kingdom; Muller, Dominique, Bâtiment BSHM, Grenoble Cedex 9, France, 38 058, LIP/PC2S, University Grenoble Alpes, dominique.muller@univ-: Hogrefe Publishing Hogrefe \& Huber Publishers Verlag Hans Huber. http://dx.doi.org/10.1027/1864-9335/a000306

Larose, S., Bernier, A., Soucy, N., \& Duchesne, S. (1999). Attachment style dimensions, network orientation and the process of seeking help from college teachers. Journal of Social and Personal Relationships. https://doi.org/10.1177/0265407599162006

Leman, P. J., \& Cinnirella, M. (2013). Beliefs in conspiracy theories and the need for cognitive closure. Frontiers in Psychology, 4. https://doi.org/10.3389/fpsyg.2013.00378

Lerner, M. J. (1980). The belief in a just world. In The belief in a just world: A fundamental delusion. https://doi.org/10.1007/978-1-4899-0448-5_2

Lynn, M., \& Snyder, C. R. (2002). Uniqueness seeking. In C. R. Snyder \& S. J. Lopez (Eds.), Handbook of positive psychology (pp. 395-410). New York, NY: Oxford University Press.

Marchlewska, M., Cichocka, A., \& Kossowska, M. (2017). Addicted to answers: Need for cognitive closure and the endorsement of conspiracy beliefs. European journal of social psychology (Vol. 48). Warsaw, Poland: Institute for Social Studies, University of Warsaw marta. marchlewska@psych.uw.edu.pl; School of Psychology, University of Kent, Canterbury, United Kingdom; Institute of Psychology, Jagiellonian University, Kraków, Poland: John Wiley \& Sons. http://dx.doi.org/10.1002/ejsp.2308

Mccauley, C., \& Jacques, S. (1979). The popularity of conspiracy theories of presidential assassination: A Bayesian analysis. Journal of Personality and Social Psychology, 37(5), 637-644. https://doi.org/10.1037/0022-3514.37.5.637

Meagher, P. K., \& O’Brien, T. C. (1979). Encyclopedic dictionary of religion (Vol. 3). Sisters of St. Joseph of Philadelphia. Washington, DC: Corpus Publications.

Mikulincer, M., Shaver, P. R., \& Pereg, D. (2003). Attachment theory and affect regulation: The dynamics, development, and cognitive consequences of attachment-related strategies. Motivation and Emotion. https://doi.org/10.1023/A:1024515519160

Miller, S. (2002). Conspiracy theories: Public arguments as coded social critiques: A Rhetorical analysis of the Twa flight 800 conspiracy theories. Argumentation and Advocacy. https://doi.org/10.1080/00028533.2002.11821576

Moulding, R., Nix-Carnell, S., Schnabel, A., Nedeljkovic, M., Burnside, E. E., Lentini, A. F., \& Mehzabin, N. (2016). Better the devil you know than a world you don't? Intolerance of uncertainty and worldview explanations for belief in conspiracy theories: Personality and individual differences (Vol. 98). Burwood, VIC, Australia: School of Psychology, Deakin University richard.moulding@deakin.edu.au; School of Psychology, Swinburne University of Technology, VIC, Australia; Moulding, Richard, Melbourne Burwood Campus, 221 Burwood Highway, Burwood, Australia, 3: Elsevier Science. http:// dx.doi.org/10.1016/j.paid.2016.04.060 
Nasir, J. J. (2009). The status of women under Islamic law and modern Islamic legislation. Boston, MA: Brill.

Palmer, R., \& Albarracín, D. (2018). Trust in science as a deterrent and a facilitator of belief in conspiracy theories: Pseudoscience preys on audiences that trust in science. University of Illinois at Urbana-Champaign. https://doi.org/10.13012/B2IDB-4469040_V1

Park, C. L. (2010). Making sense of the meaning literature: An integrative review of meaning making and its effects on adjustment to stressful life events. Psychological Bulletin. https://doi.org/10.1037/a0018301

Perry, J. C., Presniak, M. D., \& Olson, T. R. (2013). Defense mechanisms in schizotypal, borderline, antisocial, and narcissistic personality disorders. Psychiatry: Interpersonal and Biological Processes, 76(1), 32-52. https://doi.org/10.1521/psyc.2013.76.1.32

Pipes, D. (1997). Conspiracy: How the paranoid style flourishes and where it comes from. New York: Free Press.

Politico. (2011). Birthersim: Whereitallbegan. Politico. InB.Smith, \&B. Tau. Retrieved from https://www.politico.com/story/2011/04/birtherism-where-it-all-began-053563

Pratt, R. (2003). Theorizing conspiracy. Theory and Society. https://doi.org/10.1023/ A:1023996501425

Prooijen, J.-W., \& Acker, M. (2015). The influence of control on belief in conspiracy theories: Conceptual and applied extensions: Applied cognitive psychology (Vol. 29). Amsterdam, Netherlands: Netherlands Institute for the Study of Crime and Law Enforcement j.w.van.prooijen@vu.nl; Otterbein University, Westerville, OH, US; Prooijen, JanWillem, Van der Boechorststraat 1, Amsterdam, Netherlands, 1081 BT, Department of Social: John Wiley \& Sons. http://dx.doi.org/10.1002/acp.3161

Robins, R. S., \& Post, J. M. (1997). Political paranoia: The psychopolitics of hatred. New Haven, CT: Yale University Press.

Roets, A., \& Van Hiel, A. (2011). Item selection and validation of a brief, 15-item version of the need for closure scale. Personality and Individual Differences. https://doi. org/10.1016/j.paid.2010.09.004

Rolling Stones. (2017). Anatomy-of-a-fake-news-scandal. Retrieved from www. rollingstone.com/politics/politics-news/anatomy-of-a-fake-news-scandal-125877/

Rutjens, B. T., van Harreveld, F., \& van der Pligt, J. (2013). Step by step: Finding compensatory order in science. Current Directions in Psychological Science. https://doi. org $/ 10.1177 / 0963721412469810$

Shacham, S. (1983). A shortened version of the profile of mood states. Journal of Personality Assessment. https://doi.org/10.1207/s15327752jpa4703_14

Shermer, M. (2011). The believing brain: From ghosts and gods to politics and conspiracies: How we construct beliefs and reinforce them as truths. New York, NY, USA: Times Books.

Sorrentino, R. M., \& Short, J. A. C. (1986). Uncertainty orientation, motivation, and cognition. In R. M. Sorrentino \& E. T. Higgins (Eds.), The handbook of motivation and cognition: Foundations of social behavior (Vol. 1; pp. 379-403). New York: Guilford Press.

Spielberger, C. D., Gorsuch, R. L., Lushene, R., Vagg, P. R., \& Jacobs, G. A. (1983). Manual for the State-Trait Anxiety Inventory (STAI Form Y): Consulting psychologists Palo Alto. https://doi.org/10.1002/9780470479216.corpsy0943

Steele, C. M. (1988). The psychology of self-affirmation: Sustaining the integrity of the self. Advances in Experimental Social Psychology. https://doi.org/10.1016/ S0065-2601(08)60229-4

Swami, V., Chamorro-Premuzic, T., \& Furnham, A. (2010). Unanswered questions: A preliminary investigation of personality and individual difference predictors of 9/11 conspiracist beliefs: Applied cognitive psychology (Vol. 24). London, UK: Department of Psychology, University of Westminster virenswami@hotmail.com; Department of Psychology, Goldsmiths, University of London, London, United Kingdom; Department of 
Psychology, University College London, London, United Ki: John Wiley \& Sons. http://dx.doi.org/10.1002/acp.1583

Swami, V., Coles, R., Stieger, S., Pietschnig, J., Furnham, A., Rehim, S., \& Voracek, M. (2011). Conspiracist ideation in Britain and Austria: Evidence of a monological belief system and associations between individual psychological differences and realworld and fictitious conspiracy theories. British Journal of Psychology, 102(3), 443-463. https://doi.org/10.1111/j.2044-8295.2010.02004.x

Swami, V., Furnham, A., Smyth, N., Weis, L., Lay, A., \& Clow, A. (2016). Putting the stress on conspiracy theories: Examining associations between psychological stress, anxiety, and belief in conspiracy theories: Personality and individual differences (Vol. 99). Cambridge, UK: Department of Psychology, Anglia Ruskin University viren.swami@anglia. ac.uk; Department of Clinical, Educational, and Health Psychology, University College London, London, United Kingdom; Department of Psychology, University of: Elsevier Science. http://dx.doi.org/10.1016/j.paid.2016.04.084

Tesser, A. (2001). On the plasticity of self-defense. Current Directions in Psychological Science. https://doi.org/10.1111/1467-8721.00117

Tobacyk, J., \& Milford, G. (1983). Belief in paranormal phenomena: Assessment instrument development and implications for personality functioning. Journal of Personality and Social Psychology. https://doi.org/10.1037/0022-3514.44.5.1029

van den Bos, K. (2009). Making sense of life: The existential self trying to deal with personal uncertainty. Psychological Inquiry. https://doi.org/10.1080/10478400903333411

Van der Wal, R., Sutton, R. M., Lange, J., \& Braga, J. (2018). Suspicious binds: Conspiracy thinking and tenuous perceptions of causal connections between cooccurring and spuriously correlated events. European Journal of Social Psychology, 48, 970-989.

van Harreveld, F., Rutjens, B. T., Schneider, I. K., Nohlen, H. U., \& Keskinis, K. (2014). In doubt and disorderly: Ambivalence promotes compensatory perceptions of order: Journal of experimental psychology: General (Vol. 143). Amsterdam, Netherlands: Department of Social Psychology, University of Amsterdam f.vanharreveld@uva.nl; Department of Clinical Psychology, VU University of Amsterdam, Amsterdam, Netherlands; van Harreveld, Frenk, Weesperplein 4, Amsterdam, Netherlands, 1018: American Psychological Association Psychological Review Company. http://dx.doi.org/10.1037/a0036099

van Prooijen, J.-W., Douglas, K., \& De Inocencio, C. (2018). Connecting the dots: Illusory pattern perception predicts beliefs in conspiracies and the supernatural. European Journal of Social Psychology, 48, 320-335.

van Prooijen, J.-W., \& Jostmann, N. B. (2013). Belief in conspiracy theories: The influence of uncertainty and perceived morality: European journal of social psychology (Vol. 43). Amsterdam, Netherlands: Department of Social and Organizational Psychology, VU University Amsterdam jw.van.prooijen@psy.vu.nl; University of Amsterdam, Amsterdam, Netherlands; van Prooijen, Jan-Willem, Van den Boechorststraat 1, Amsterdam, Netherlands, 1081: John Wiley \& Sons. http://dx.doi.org/10.1002/ejsp.1922

van Prooijen, J.-W., \& Krouwel, A. P. M. (2015). Mutual suspicion at the political extremes: How ideology predicts belief in conspiracy theories. In M. Bilewicz, A. Cichocka, \& W. Soral (Eds.), The psychology of conspiracy (pp. 79-98). New York and London: Routledge/ Taylor \& Francis Group.

van Prooijen, J.-W., \& van Dijk, E. (2014). When consequence size predicts belief in conspiracy theories: The moderating role of perspective taking. Journal of Experimental Social Psychology, 55, 63-73. https://doi.org/10.1016/j.jesp.2014.06.006

van Prooijen, J.-W., \& van Lange, P. A. M. (2014). The social dimension of belief in conspiracy theories. In Power, politics, and paranoia: Why people are suspicious of their leaders. https://doi.org/10.1017/CBO9781139565417.017 
Webster, D. M., \& Kruglanski, A. W. (1994). Individual differences in need for cognitive closure. Journal of Personality and Social Psychology. https://doi.org/10.1037/0022-3514. 67.6.1049

Whitson, J. A., \& Galinsky, A. D. (2008). Lacking control increases illusory pattern perception. Science. https://doi.org/10.1126/science.1159845

Wichman, A. L., Brinol, P., Petty, R. E., Rucker, D. D., Tormala, Z. L., \& Weary, G. (2010). Doubting one's doubt: A formula for confidence? Journal of Experimental Social Psychology, 46(2), 350-355. https://doi.org/10.1016/j.jesp.2009.10.012

Wilson, M. S., \& Rose, C. (2014). The role of paranoia in a dual-process motivational model of conspiracy belief. Cambridge: Cambridge University Press. https://doi.org/10.1017/ CBO9781139565417.019 